\title{
Fischer Carbene Complexes of Iridium(I) for Application in Catalytic Transfer Hydrogenation
}

\author{
G. Kabelo Ramollo, Ian Strydom, Manuel A. Fernandes, Andreas Lemmerer, Stephen O. Ojwach, \\ Juanita L. van Wyk, and Daniela I. Bezuidenhout*
}

Cite This: Inorg. Chem. 2020, 59, 4810-4815

Read Online

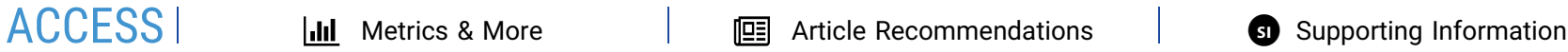

ABSTRACT: New examples of the very rare class of iridium(I) Fischer carbene complexes (FCCs) are reported from the facile transmetalation from group 6 FCCs. Postcomplexation modification of either the carbene ligand or the ancillary coligands results in a tunable $\operatorname{Ir}^{\mathrm{I}}$ metal center, for unprecedented application as a (pre)catalyst in a benchmark transfer hydrogenation reaction. The introduction of an aminocarbene ligand with a pendant $\mathrm{N}$-donor moiety capable of hemilabile coordination yielded the best catalytic results with

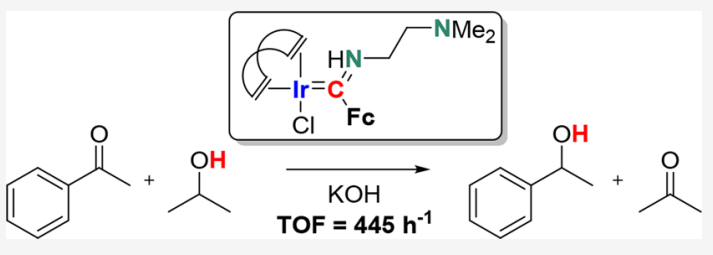
turnover frequencies reaching $445 \mathrm{~h}^{-1}$ and requiring $0.1 \mathrm{~mol} \%$ catalyst and $0.5 \mathrm{~mol} \%$ base loading, respectively.

$\mathrm{T}$ he ability to finely tune the electronic poles of the metalcarbon (double) bond results in unique chemical reactivity. In the case of heteroatom-stabilized Fischer carbene complexes (FCCs), ${ }^{1}$ a resurgence in the interest of this versatile chemical bond has been seen to go beyond the traditional applications in template organic synthesis to especially photophysical, optical, and sensing applications. ${ }^{2}$ However, applications in catalysis are still lacking due to the inherent difficulties associated with preparing FCCs of the late transition metals. The requirements of low metal oxidation states and the presence of modifiable carbonyl or isonitrile ligands for nucleophilic attack in the preparation of FCCs, ${ }^{3}$ often in the presence of halide coligands, are limiting. The use of carbene transfer reactions from group 6 metals have been employed in catalytic transmetalation reactions for alkene and allene cyclization reactions, but reports of isolated latetransition-metal FCCs are rare. ${ }^{4}$ This is primarily due to the self-dimerization observed for the electrophilic carbene ligands, ${ }^{5}$ although appropriate electron-donating coligands or donating Fischer carbene ligand substituents have enabled the isolation of rhodium(I) FCCs that are stable at room temperature. $^{6}$ In this regard, we have reported ferrocenyl Fischer carbene ligands coordinated to rhodium(I) that were stable to both atmospheric conditions and elevated temperatures and pressures. More importantly, we could show that these $\mathrm{Rh}^{\mathrm{I}}$ FCCs were efficient in catalyzing the hydroformylation of 1-octene. In this work, the strategy of transmetalation is extended to the preparation of unprecedented iridium(I) FCC analogues, and the use of these group 9 transition-metal FCCs as catalyst precursors in the transfer hydrogenation reaction is investigated.

Pentacarbonyl tungsten $(0)$ ethoxycarbene complexes, containing the strongly electron donating carbene substituent $p$ $N, N$-dimethylaniline $(p-D M A)^{8}$ or the organometallic fragment ferrocenyl $(\mathrm{Fc})$, ${ }^{9}$ were employed as the precursor tungsten(0) FCCs for the preparation of the corresponding $\operatorname{Ir}^{\mathrm{I}}$ FCCs 1 and 2 (see Scheme 1), following a methodology

Scheme 1. Carbene Transfer from Tungsten(0) FCCs for the Preparation of 1-3

$$
\begin{aligned}
(\mathrm{OC})_{5} \mathrm{~W}=\mathrm{Ar}_{\mathrm{Ar}} & \stackrel{\mathrm{Ir}(\mathrm{cod}) \mathrm{Cl}]_{2}}{\mathrm{CH}_{2} \mathrm{Cl}_{2}, \mathrm{rt}} \\
1 \mathrm{Ar} & =p-\mathrm{DMA}(91 \%) \\
2 \mathrm{Ar}=\mathrm{Fc}(77 \%) & \\
3 \mathrm{Ar} & =\mathrm{Cp} \mathrm{Cpe}^{\prime}(\mathrm{CO})_{3}(75 \%)
\end{aligned}
$$

similar to that employed for the analogous rhodium(I) FCC with a ferrocenyl $(\mathrm{Fc})$ carbene substituent, $[\mathrm{Rh}(\mathrm{cod}) \mathrm{Cl}\{\mathrm{C}$ $(\mathrm{OEt}) \mathrm{Fc}\}]$ ( cod = 1,5-cyclooctadiene). ${ }^{7}$ The carbene transfer reaction ensues with stirring of an equimolar mixture of the group 6 precursor FCC with the dimer $[\operatorname{Ir}(\operatorname{cod}) \mathrm{Cl}]_{2}$, in dichloromethane solvent, at room temperature. The reaction progress was monitored with thin-layer chromatography (tlc), and reaction completion was observed within $24 \mathrm{~h}$. Surprisingly, employing the precursor $\left[\mathrm{W}(\mathrm{CO})_{5}\{\mathrm{C}(\mathrm{OEt})\right.$ $\left.\left.\mathrm{Cp}^{\prime} \operatorname{Re}(\mathrm{CO})_{3}\right\}\right]^{10}\left(\mathrm{Cp}^{\prime}=\right.$ cyclopentadienyl $)$, using the same methodology, gave facile access to the FCC 3 (Scheme 1), despite the known electrophilicity of this carbene ligand as a result of the "draining" of electron density by the $-\operatorname{Re}(\mathrm{CO})_{3}$ moiety. ${ }^{11}$ Previously, Fischer carbene ligands containing

Received: January 10, 2020

Published: March 26, 2020 
electron-withdrawing substituents have resulted exclusively in kinetic and thermal decomposition dimerization products. ${ }^{5-7}$

Examples of iridium FCCs are very rare. These include the iridium(III) FCCs generated by $\mathrm{C}-\mathrm{H}$ bond activation of ethers as reported by the groups of Carmona ${ }^{12}$ and Grubbs, ${ }^{13}$ respectively. In addition to this class of compounds, two isolated examples of $\mathrm{Ir}^{\mathrm{III}}$ heteroatom-stabilized carbene complexes have been reported, ${ }^{14}$ while the use of either a cyclic aminocarbene ligand ${ }^{15}$ or an acyclic diaminocarbene ligand $^{16}$ has paved the way for free carbene generation and complexation to the only two examples of $\mathrm{Ir}^{\mathrm{I}}$ FCCs preceding this report. In our case, such stringent reaction conditions could be circumvented via direct carbene transfer reactions (see the Supporting Information for complex synthesis and characterization). Simple substitution reactions could be employed to significantly alter the electronic environment around the central $\mathrm{Ir}^{\mathrm{I}}$, by replacement of the cod ligands with two carbonyl ligands $(7,8)$ or by aminolysis of the ethoxycarbenes with either $n$-propylamine or $N, N$-dimethyl1,2-diaminoethane $(\mathbf{4 - 6 , 8})$ (Scheme 2). The latter diamine

\section{Scheme 2. Postcomplexation Modification to Yield} Complexes 4-8

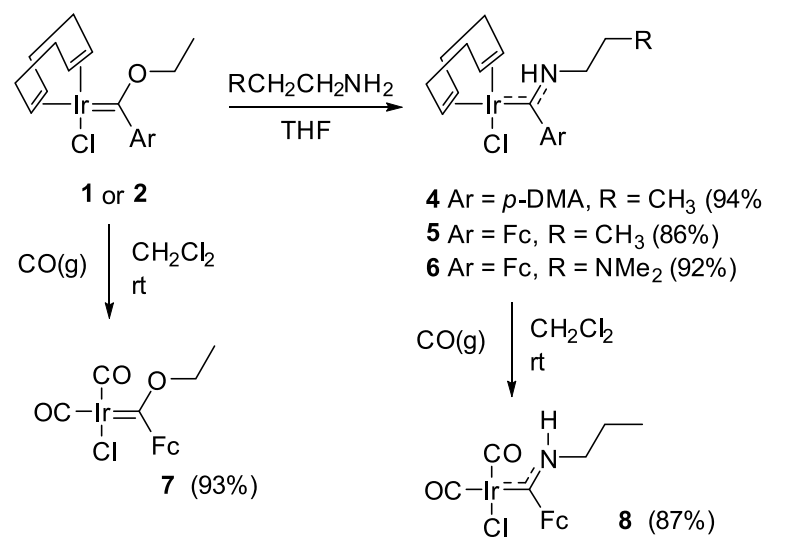

was employed to investigate the possibility of chelation to form a metallacyclic FC ligand. The tertiary amino group remains as an untethered pendant amine, and virtually no difference in the spectroscopic characteristics of complexes 5 and $\mathbf{6}$ is observed (Supporting Information). Nevertheless, the pendant amine provides the opportunity for hemilabile chelation activity of the FCC ligand during catalysis (vide infra). As expected, replacement of the ethoxycarbene substituent with an amino group leads to a significant upfield shift (>40 ppm) in the ${ }^{13} \mathrm{C}$ NMR resonances of the carbene carbon atoms due to the increased stabilization of the electrophilic carbene carbon by the nitrogen lone pair. ${ }^{17}$ The ethoxycarbene complexes 1-3 and 7 display carbene atom chemical shifts in the range of 275.1-286.6 ppm, while the aminocarbene complexes 4-6 and 8 have carbene carbon atoms resonating in the range 232.6-245.5 ppm (see Table 1).

Single crystals suitable for diffraction could be grown for complexes $\mathbf{1 - 5}$ and 7 by slow diffusion of hexane/dichloromethane layered solutions, and the molecular structures are shown in Figure 1. Crystallographic data and selected bond lengths and angles are given in Tables $\mathrm{S} 1$ and $\mathrm{S} 2$ in the Supporting Information. A pseudo-square-planar geometry around the central iridium atom is observed in all cases. The $\mathrm{Ir}-\mathrm{C}_{\text {carbene }}$ bond lengths are, in general, shorter for the
Table 1. Selected Spectroscopic Data for Complexes 1-8

\begin{tabular}{ccccc}
{$[\mathrm{Ir}]$} & ${ }^{13} \mathrm{C} \delta\left(\mathrm{C}_{\text {carbene }}\right)$ & ${ }^{13} \mathrm{C} \delta(\mathrm{CO})$ & $\mathrm{IR}^{f} \nu(\mathrm{CO})\left(\mathrm{cm}^{-1}\right)$ & $\mathrm{TEP}^{g}\left(\mathrm{~cm}^{-1}\right)$ \\
\hline $\mathbf{1}$ & $276.7^{a}$ & & & $2052^{h}$ \\
$\mathbf{2}$ & $286.6^{a}$ & & & \\
3 & $275.1^{a}$ & & & $2063^{h}$ \\
$\mathbf{4}$ & $240.3^{a}$ & & & $2049^{h}$ \\
$\mathbf{5}$ & $245.4^{b}$ & & & \\
6 & $245.5^{b}$ & & & $2043^{h}$ \\
7 & $277.4^{c}$ & $184.1^{d} 170.1^{e}$ & $1987,^{e} 2069^{d}$ & 2055 \\
8 & $232.5^{b}$ & $183.6^{d} 170.3^{e}$ & $198,^{e} 2063^{d}$ & 2050
\end{tabular}

${ }^{a}$ Recorded in $\mathrm{CD}_{2} \mathrm{Cl}_{2} \cdot{ }^{b}$ Recorded in $\mathrm{CDCl}_{3} .{ }^{c}$ Recorded in $\mathrm{C}_{6} \mathrm{D}_{6} \cdot{ }^{d} \mathrm{CO}$ ligand trans to carbene. ${ }^{e} \mathrm{CO}$ ligand trans to $\mathrm{Cl} .{ }^{f}$ Recorded in $\mathrm{CH}_{2} \mathrm{Cl}_{2}$. ${ }^{g}$ Calculated using the linear regression model TEP $=0.8475$ $\left[\nu_{\text {av }}(\mathrm{CO}) \mathrm{Ir}\right]+336.2 \mathrm{~cm}^{-1} \cdot{ }^{19}{ }^{h}$ Calculated for the nonisolated dicarbonyl analogues of these complexes; see section S3 in the Supporting Information.

ethoxycarbene complexes, in comparison to the aminocarbene complexes, while the $\mathrm{C}_{\text {carbene }}-\mathrm{N}$ bond lengths are indicative of $\mathrm{C}_{\text {carbene }}-\mathrm{N}$ bond orders greater than 1 (ranging from 1.315(2) to 1.305 (5) $\AA$, respectively, for 4 and 5), commensurate with the upfield ${ }^{13} \mathrm{C}$ NMR shifts observed for the aminocarbene carbon atoms. ${ }^{17}$ Notably, the "electron-sink" cyclopentadienyl rhenium tricarbonyl moiety results in the shortest $\mathrm{Ir}-\mathrm{C}_{\text {carbene }}$ bond length for 3 (1.954(7) $\AA$ ), due to the increased $\pi$ backbonding required for the significantly more electrophilic ethoxycarbene ligand in comparison to the $p$-DMA- and Fcsubstituted FCCs 1 and 2, with $\mathrm{Ir}-\mathrm{C}_{\text {carbene }}$ bond lengths of $1.972(2)$ and 1.963(9) A, respectively. In contrast, the cod coligand substitution by two carbonyl ligands has the opposite effect, where introduction of the strongly $\pi$ acidic CO ligands and competing requirement for $\pi$ back-donation result in a significantly longer $\operatorname{Ir}-\mathrm{C}_{\text {carbene }}$ bond length for 7 (2.065(9) $\AA$ ), in comparison to the cod analogue 2 (1.963(9) $\AA$ ). Similarly, the shortest $\mathrm{C}_{\text {carbene }}-\mathrm{O}$ bond length is seen for 7 (1.311(10) $\AA$ ) and is indicative of significant participation of the ethoxy O atom toward carbene carbon stabilization. However, all of the $\mathrm{Ir}-\mathrm{C}_{\text {carbene }}$ bond lengths $(1.954(7)-2.065(9) \AA)$ are significantly shorter in comparison to those of the only other known structure of an $\operatorname{Ir}^{I}$ FCC, with $\operatorname{Ir}-C_{\text {carbene }}=2.094(5) \AA{ }^{15 \mathrm{a}}$ attesting to the greater $\mathrm{Ir}-\mathrm{C}$ bond order and degree of backdonation. The presence of the coordinated carbonyl ligands also provides the opportunity to calculate Tolman electronic parameters (TEPs) for the carbene ligands as an estimation of the electron-donating ability of the $: \mathrm{C}(\mathrm{OEt}) \mathrm{Fc}$ and $: \mathrm{C}$ $\left(\mathrm{NH}^{n} \mathrm{Pr}\right) \mathrm{Fc}$ carbene ligands, ${ }^{18}$ in comparison to what is known for a wide range of N-heterocyclic carbenes (NHCs). The TEP values were determined from a linear regression formula ${ }^{19}$ and match the values previously obtained for the $\mathrm{Rh}^{\mathrm{I}}$ analogues, ${ }^{7}$ to confirm the enhanced donating ability of aminoFCs over that of alkoxy-FCs and generally the strong donating ability of the ferrocenyl-functionalized FCs. ${ }^{15 a}$ In order to complete the calculated TEPs for a series of carbene ligands, TEPs for the dicarbonyl analogues of complexes 1, 3, 4, and 6 were also determined and the IR spectra measured (section S3 in the Supporting Information). The TEPs range over $20 \mathrm{~cm}^{-1}$, from $\mathrm{TEP}=2043 \mathrm{~cm}^{-1}$ for the ligand $\mathrm{C}\left(\mathrm{NH}\left(\mathrm{CH}_{2}\right)_{2} \mathrm{NMe}_{2}\right) \mathrm{Fc}$, indicating that this is the most donating ligand, to TEP $=2063$ $\mathrm{cm}^{-1}$ for the $\mathrm{FC}: \mathrm{C}(\mathrm{OEt}) \mathrm{Cp}^{\prime} \operatorname{Re}(\mathrm{CO})_{3}$ as the most electrophilic/least donating carbene ligand.

The ubiquitous NHC ligands are also widely employed as the ligand of choice for both $\mathrm{Ir}^{\mathrm{III}}$ - and $\mathrm{Ir}^{\mathrm{I}}$-mediated catalytic 


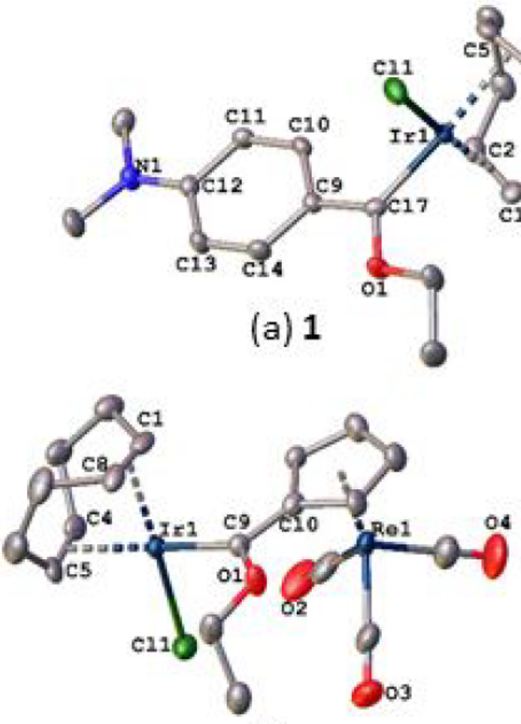

(c) 3

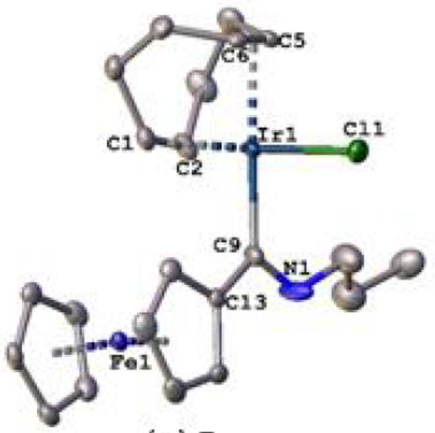

(e) 5
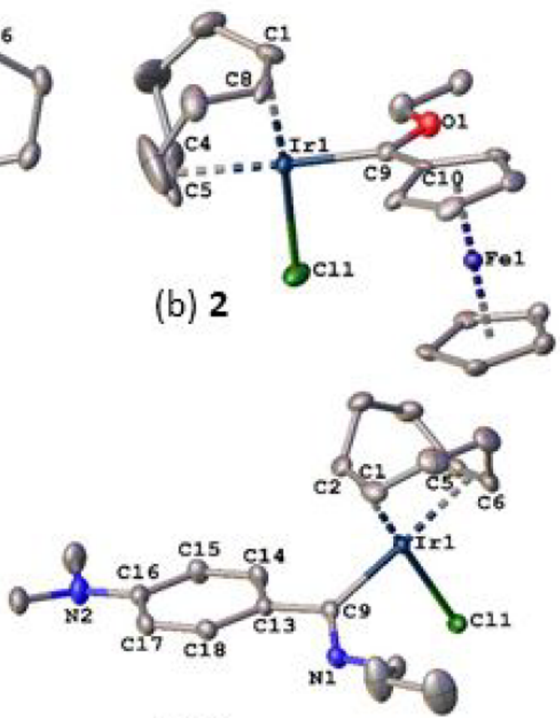

(d) 4

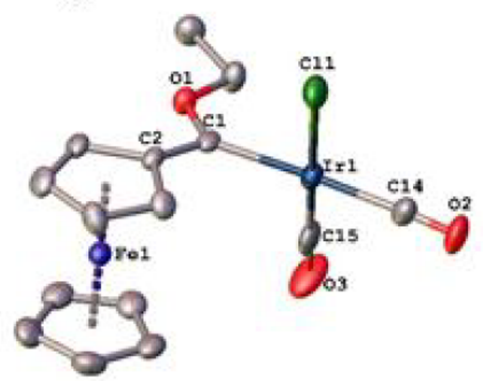

(f) 7

Figure 1. Ellipsoid plots of complexes 1-5 and 7 (50\% probability level). Hydrogen atoms have been omitted for clarity. Selected bond lengths $(\AA): 1, I r-C_{\text {carbene }} 1.972(2), C_{\text {carbene }}-\mathrm{O} 1.349(2), C_{\text {carbene }}-C_{\text {ipso }} 1.443(3) ; 2, \mathrm{Ir}-\mathrm{C}_{\text {carbene }} 1.963(9), \mathrm{C}_{\text {carbene }}-\mathrm{O} 1.317(11), \mathrm{C}_{\text {carbene }}-\mathrm{C}_{\text {ipso }} 1.458(13)$; 3, Ir $-\mathrm{C}_{\text {carbene }} 1.954(7), \mathrm{C}_{\text {carbene }}-\mathrm{O} 1.319(10), \mathrm{C}_{\text {carbene }}-\mathrm{C}_{\text {ipso }} 1.449(12) ; 4, \mathrm{Ir}-\mathrm{C}_{\text {carbene }} 2.0145(17), \mathrm{C}_{\text {carbene }}-\mathrm{N} 1.315(2), \mathrm{C}_{\text {carbene }}-\mathrm{C}_{\text {ipso }} 1.475(2) ; 5$, $\mathrm{Ir}-\mathrm{C}_{\text {carbene }} 2.029(3), \mathrm{C}_{\text {carbene }}-\mathrm{N} 1.305(5), \mathrm{C}_{\text {carbene }}-\mathrm{C}_{\text {ipso }} 1.458(5) ; 7, \mathrm{Ir}-\mathrm{C}_{\text {carbene }} 2.065(9), \mathrm{C}_{\text {carbene }}-\mathrm{O} 1.311(10), \mathrm{C}_{\text {carbene }}-\mathrm{C}_{\text {ipso }} 1.430(12)$;

hydrogen transfer reactions, although examples of iridium(I) catalysts are less common. ${ }^{22}$ However, to our knowledge, only one example of an acyclic carbene $\operatorname{Ir}^{\mathrm{I}}$ complex active in transfer hydrogenation has been reported. ${ }^{15 a}$ The stability displayed by complexes 1-8 with the electronically modifiable FCC ligands portended their use as catalysts in the transfer hydrogenation of ketones. ${ }^{20}$ Acetophenone was employed as the model substrate, with isopropyl alcohol solvent as the sacrificial hydrogen donor. The reaction conditions were optimized by variation of reaction times, catalysts, and base loadings (see Table S4, section S6, in the Supporting Information). Finally, the catalytic experiments were conducted in isopropyl alcohol solvent at reflux temperature, with $0.1 \mathrm{~mol} \%$ catalyst and 0.5 mol \% base loading, with respect to the substrate acetophenone (Table 2). The addition of mercury to the catalytic reaction (entry 11, Table 2) did not result in a variation of either the conversion or calculated TOF in comparison to the mercury-free equivalent entry 6 of Table 2, indicative of a homogeneous mode of action. ${ }^{21}$ In addition, a stability test was conducted whereby complex 6 and a stoichiometric amount of base $\mathrm{KOH}$ was refluxed in isopropyl alcohol solvent for $16 \mathrm{~h}$. Both the ${ }^{1} \mathrm{H}$ and ${ }^{13} \mathrm{C}$ NMR spectra provide clear evidence that the coordinated carbene ligand remains intact (Figures S22 and S23 in the Supporting Information).

In general, more electron donating carbene ligands, e.g. aminocarbene (entry 4, Table 2) vs ethoxycarbene (entry 1, Table 2) or Fc-FC (entry 2, Table 2) and p-DMA-FC (entry 1, Table 2) vs $\mathrm{Cp}^{\prime} \mathrm{Re}(\mathrm{CO})_{3}$-FC (entry 3, Table 2), perform better, as was also found to be the case for NHCs. ${ }^{2 \mathrm{~b}}$ This is also true for the coligands cod (entries 2 and 5, Table 2) vs $(\mathrm{CO})_{2}$ (entries 7 and 8 , Table 2), where the overall electrophilic nature of the coordination sphere influences the performance of the catalytic metal center. However, the most noteworthy observation is the best performance of complex 6 (entry 6, Table 2), in comparison to not only its ethoxy analogue $\mathbf{2}$ (entry 2) but also its monoamine analogue $\mathbf{5}$ (entry 5). Indeed, a yield of $89 \%$ is achieved after a reaction time of 2 $\mathrm{h}$, giving rise to a calculated TOF of $445 \mathrm{~h}^{-1}$, employing a 0.1 mol \% catalyst loading, and a low catalyst/base ratio of $1 / 5$. This result rivals that of the best-performing $\operatorname{Ir}^{\mathrm{I}} \mathrm{NHC}$ catalysts previously reported. $^{22}$ The excellent performance of this (pre)catalyst 6 can be ascribed not only to the donating ability of the Fc substituent for the electrophilic carbene ligand but possibly also to the synergistic benefits associated with the inclusion of a secondary catalytically active metal center, where $\mathrm{Fe}^{\mathrm{II}}$ is known to be active in transfer hydrogenation. ${ }^{23}$ More 
Table 2. Reduction of Acetophenone with Iridium(I) FCCs $1-8^{a}$

\begin{tabular}{cccccc} 
Entry & $\begin{array}{c}\text { Time } \\
(\mathrm{h})\end{array}$ & $\%$ Conversion $^{b}$ & $\mathrm{TOF}^{c}\left(\mathrm{~h}^{-1}\right)$ \\
\hline 1 & $\mathbf{1}$ & 16 & $22(2.4)$ & $14(1.6)$ \\
3 & $\mathbf{2}$ & 16 & $71(2.4)$ & $45(1.3)$ \\
4 & $\mathbf{3}$ & 16 & $13(1.7)$ & $8(0.8)$ \\
5 & $\mathbf{5}$ & 16 & $87(1.7)$ & $55(1.3)$ \\
6 & $\mathbf{6}$ & 16 & $97(1.0)$ & $45(4.9)$ \\
7 & $\mathbf{7}$ & 16 & $23(2.8)$ & $14(1.3)$ \\
8 & $\mathbf{8}$ & 16 & $51(5.4)$ & $32(3.3)$ \\
9 & $\mathbf{4}$ & 2 & $55(6.2)$ & $273(31.2)$ \\
10 & $\mathbf{6}$ & 2 & $89(4.3)$ & $445(22.0)$ \\
11 & $\mathbf{6}+\mathrm{Hg}^{d}$ & 16 & $98(0.0)$ & $61(0.0)$ \\
\hline
\end{tabular}

${ }^{a}$ All reactions were done as triplicate in high-pressure reaction tubes fitted with a greaseless high-vacuum stopcock under an argon atmosphere. Optimized reaction conditions: iridium/base/substrate $1 / 5 / 1000$ in isopropyl alcohol at reflux temperature. Reactions were monitored by gas chromatography using $n$-decane as internal standard. ${ }^{b}$ The reactions were performed in triplicate, and standard deviations are indicated in parentheses. ${ }^{c}$ Average turnover frequency (TOF) $(($ mol of product $) /((\mathrm{mmol}$ of catalyst $) \mathrm{h}))$ determined at the reaction time. ${ }^{d}$ Excess $\mathrm{Hg}(\mathrm{l})$ was placed in the reaction flask.

importantly, the improved activity of the catalyst 6 in comparison to 5 , where 6 contains an aminocarbene ligand carrying a pendant $\mathrm{N}$-donor moiety, is indicative of the potential hemilabile role of this aminocarbene ligand in the catalytic cycle, as proven for other iridium-mediated transfer hydrogenation catalysts. ${ }^{22 \mathrm{~d}-\mathrm{f}, 24}$

In summary, rare examples of monoheteroatom-stabilized carbene complexes of $\operatorname{Ir}^{1}$ are accessible via facile carbene transfer from group 6 FCCs. This paves the way to tunable carbene ligands coordinated to $\mathrm{Ir}^{\mathrm{I}}$, via simple ligand modification reactions for new examples of catalytically relevant iridium(I) FCCs. Introduction of a donor-functionalized FCC ligand with a pendant $\mathrm{N}$ donor yields an $\mathrm{Ir}^{\mathrm{I}}$ (pre)catalyst for the hydrogen transfer reaction from isopropyl alcohol to acetophenone with high efficiency, requiring both a low catalyst and base loading for this benchmark reaction. This work reports but the second example of acyclic carbene complexes of iridium(I) for catalytic application in hydrogen transfer reactions. The catalytic activities of the $\operatorname{Ir}^{\mathrm{I}}$ complexes are largely controlled by the electrophilicity of the $\operatorname{Ir}^{\mathrm{I}}$ metal center.

\section{ASSOCIATED CONTENT}

\section{SI Supporting Information}

The Supporting Information is available free of charge at https://pubs.acs.org/doi/10.1021/acs.inorgchem.0c00079.

Experimental details, including synthesis, NMR and FTIR spectra, SC-XRD, and catalysis details (PDF)

\section{Accession Codes}

CCDC 1970902-1970907 contain the supplementary crystallographic data for this paper. These data can be obtained free of charge via www.ccdc.cam.ac.uk/data_request/cif, or by emailing data_request@ccdc.cam.ac.uk, or by contacting The Cambridge Crystallographic Data Centre, 12 Union Road, Cambridge CB2 1EZ, UK; fax: +44 1223336033.

\section{AUTHOR INFORMATION}

\section{Corresponding Author}

Daniela I. Bezuidenhout - Molecular Sciences Institute, School of Chemistry, University of the Witwatersrand, Johannesburg 2050, South Africa; Laboratory of Inorganic Chemistry, Environmental and Chemical Engineering, University of Oulu, 90014 Oulu, Finland; 이이.org/0000-0001-7776-8227; Email: daniela.bezuidenhout@oulu.fi

\section{Authors}

G. Kabelo Ramollo - Molecular Sciences Institute, School of Chemistry, University of the Witwatersrand, Johannesburg 2050, South Africa

Ian Strydom - Chemistry Department, University of Pretoria, 0028 Pretoria, South Africa

Manuel A. Fernandes - Molecular Sciences Institute, School of Chemistry, University of the Witwatersrand, Johannesburg 2050, South Africa; O orcid.org/0000-0002-4849-5335

Andreas Lemmerer - Molecular Sciences Institute, School of Chemistry, University of the Witwatersrand, Johannesburg 2050, South Africa; (1) orcid.org/0000-0003-1569-2831

Stephen O. Ojwach - School of Chemistry and Physics, University of KwaZulu-Natal, Pietermaritzburg, South Africa

Juanita L. van Wyk - Molecular Sciences Institute, School of Chemistry, University of the Witwatersrand, Johannesburg 2050, South Africa

Complete contact information is available at:

https://pubs.acs.org/10.1021/acs.inorgchem.0c00079

\section{Notes}

The authors declare no competing financial interest.

\section{ACKNOWLEDGMENTS}

The authors gratefully acknowledge the National Research Foundation, South Africa (NRF 115642; NRF 94784; NRF 100119; NRF 111705), University of KwaZulu-Natal (S.O.O.), and Sasol Technology R\&D Pty. Ltd. (South Africa) for financial support (D.I.B.).

\section{ABBREVIATIONS}

FCC, Fischer carbene complex; NHC, N-heterocyclic carbene; Fc, ferrocenyl; $p$-DMA, para- $N, N$-dimethylaniline; cod, 1,5cyclooctadiene; tlc, thin-layer chromatography; TOF, turnover frequency

\section{REFERENCES}

(1) For recent reviews on FCCs, see: (a) Munz, D. Pushing electrons - Which carbene ligand for which application? Organometallics 2018, 37, 275. (b) Raubenheimer, H. G. Fischer carbene complexes remain favourite targets, and vehicles for new discoveries. Dalton Trans. 2014, 43, 16959. (c) Bezuidenhout, D. I.; Lotz, S.; Liles, D. C.; van der Westhuizen, B. Recent advances in the field of multicarbene and multimetal carbene complexes of the Fischer-type. Coord. Chem. Rev. 2012, 256, 479. (d) Dzik, W. I.; Zhang, X. P.; de Bruin, B. Redox noninnocence of carbene ligands: carbene radicals in 
(catalytic) C-C bond formation. Inorg. Chem. 2011, 50, 9896. (e) Fernandez, I.; Cossio, F. P.; Sierra, M. A. Photochemistry of group 6 Fischer carbene complexes: Beyond the photocarbonylation reaction. Acc. Chem. Res. 2011, 44, 479. (f) Fernandez-Rodriguez; Garcia-Garcia, P.; Aguilar, E. Chem. Commun. 2010, 46, 7670. (g) Dotz, K. H.; Stendel, J., Jr. Fischer carbene complexes in organic synthesis: metal-assisted and metal-templated reactions. Chem. Rev. 2009, 109, 3227. (h) Barluenga, J.; Santamaria, J.; Tomas, M. Synthesis of heterocycles via group VI Fischer carbene complexes. Chem. Rev. 2004, 104, 2259.

(2) (a) Skoch, K.; Cisarova, I.; Uhlik, F.; Stepnicka, P. Comparing the reactivity of isomeric phosphinoferrocene nitrile and isocyanide in Pd(II) complexes: synthesis of simple coordination compounds vs. preparation of P-chelated insertion products and Fischer-type carbenes. Dalton Trans. 2018, 47, 16082. (b) Lazo-Jimenez, R. E.; Ortega-Alfaro, M. C.; Lopez-Cortes, J. G.; Alvarez-Toledano, C.; Chavez-Carvayar, J. A.; Ignes-Mullol, J.; Gonzalez-Torres, M.; Carreon-Castro, P. Nanostructures thin films obtained from Fischer aminocarbene complexes. Materials 2016, 9, 167. (c) Srivastava, P.; Ghasemi, M.; Ray, N.; Sarkar, A.; Kocabova, J.; Lachmanova, S.; Hromadova, M.; Boujday, S.; Cauteruccio, S.; Thakare, P.; Licandro, E.; Fosse, C.; Salmain, M. Appl. Surf. Sci. 2016, 385, 47. (d) Bertolino, M. C.; Granados, A. M. Synthesis in situ of gold nanoparticles by a dialkynyl Fischer carbene complex anchored to glass surfaces. Appl. Surf. Sci. 2016, 383, 375. (e) Arrowsmith, R. L.; Atkin, A. J.; Botchway, S. W.; Fairlamb, I. J. S.; Lynnam, J. M.; Moir, J. W. B.; Pascu, S. I.; Ward, J. S.; Zhang, W.-Q. Confocal and fluorescence lifetime imaging sheds light on the fate of a pyrene-tagged carbon monoxide-releasing Fischer carbene chromium complex. Dalton Trans. 2015, 44, 4957. (f) Ponniah S, J.; Barik, S. K.; Thakur, A.; Ganesamoorthi, R.; Ghosh, S. Organometallics 2014, 33, 3096.

(3) Fischer, E. O.; Maasbol, A. On the existence of a tungsten carbonyl carbene complex. Angew. Chem., Int. Ed. Engl. 1964, 3, 580.

(4) For an overview, see: Gomez-Gallego, M.; Mancheno, M. J.; Sierra, M. A. Catalytic transmetalation from group 6 Fischer carbene complexes: an emerging powerful tool in organic synthesis. Acc. Chem. Res. 2005, 38, 44.

(5) Fernandez, I.; Mancheno, M. J.; Vicente, R.; Lopez, L. A.; Sierra, M. A. Transmetalation reactions from Fischer carbene complexes to late transition metals: A DFT study. Chem. - Eur. J. 2008, 14, 11222. (6) (a) Barluenga, J.; Vicente, R.; Lopez, L. A.; Tomas, M. Chromium(0)-rhodium(I) metal exchange: Synthesis and X-ray structure of new Fischer (NHC)carbene complexes of rhodium(I). J. Organomet. Chem. 2006, 691, 5642. (b) Barluenga, J.; Vicente, R.; Lopez, L. A.; Rubio, E.; Tomas, M.; Alvarez-Rua, C. New Fischer carbene complexes of rhodium(I): Preparation and 2-cyclopentenone ring synthesis by annelation to alkynes. J. Am. Chem. Soc. 2004, 126, 470. (c) Gottker-Schnetmann, I.; Aumann, R.; Bergander, K. Metal ion mediated transfer and cleavage of diaminocarbene ligands. Organometallics 2001, 20, 3574.

(7) Ramollo, G. K.; Lopez-Gomez, M. J.; Liles, D. C.; Matsinha, L. C.; Smith, G. S.; Bezuidenhout, D. I. Rhodium(I) ferrocenylcarbene complexes: synthesis, structural determination, electrochemistry, and application as hydroformylation catalyst precursors. Organometallics 2015, 34, 5745 .

(8) Lotz, S.; van den Berg, M.; Dillen, J. L. M. Metallacyclic carbene complexes of chromium $(0)$. The crystal and molecular structure of a chromium(0) complex with an aminoarylcarbene chelating ligand. Transition Met. Chem. 1988, 13, 170.

(9) (a) Connor, J. A.; Lloyd, J. P. Ferrocenyl carbene complexes of chromium, tungsten and manganese. Models of the $\alpha$-ferrocenyl carbonium ion. J. Chem. Soc., Dalton Trans. 1972, 14, 1470. (b) van der Westhuizen, B.; Swarts, P. J.; Strydom, I.; Liles, D. C.; Fernandez, I.; Swarts, J. C.; Bezuidenhout, D. I. Electrochemical illumination of thienyl and ferrocenyl chromium(0) Fischer carbene complexes. Dalton Trans. 2013, 42, 5367.

(10) For the synthesis and characterisation of the new ethoxy analogue precursor $\left[\mathrm{W}(\mathrm{CO})_{5}\left\{\mathrm{C}(\mathrm{OEt}) \mathrm{Cp}^{\prime} \operatorname{Re}(\mathrm{CO})_{3}\right\}\right]$, see the Supporting Information.
(11) The methoxycarbene analogue of this precursor, $\left[\mathrm{W}(\mathrm{CO})_{5}\left\{\mathrm{C}(\mathrm{OMe}) \mathrm{Cp}^{\prime} \operatorname{Re}(\mathrm{CO})_{3}\right\}\right]$, has been previously reported by: Lage, M. L.; Fernandez, I.; Mancheno, M. J.; Gomez-Gallego, M.; Sierra, M. A. The electronic structure and photochemistry of group 6 bimetallic (Fischer) carbene complexes: Beyond the photocarbonylation reaction. Chem. - Eur. J. 2010, 16, 6616.

(12) Carmona, E.; Paneque, M.; Santos, L. L.; Salazar, V. Iridium carboxycarbene complexes by $\mathrm{C}-\mathrm{H}$ bond activation of aliphatic ethers and of alkyl aryl ethers. Coord. Chem. Rev. 2005, 249, 1729.

(13) Whited, M. T.; Grubbs, R. H. Synthesis and reactivity of iridium(III) dihydrido aminocarbenes. Organometallics 2008, 27, 5737.

(14) (a) Luecke, H. F.; Bergman, R. G. Synthesis, structural characterisation, and chemistry of a monomeric cationic iridium carbene complex. J. Am. Chem. Soc. 1998, 120, 11008. (b) O'Connor, J. M.; Pu, L.; Rheingold, A. L. J. Am. Chem. Soc. 1990, 112, 6232.

(15) (a) Yasue, R.; Yoshida, K. Synthesis and application of planar chiral cyclic (amino)(ferrocenyl)carbene ligands bearing $\mathrm{FeCp}^{*}$ group. Organometallics 2019, 38, 2211. (b) Fraser, R. J.; Roper, W. R; Stone, F. G. A. Carbene complexes of iridium, rhodium, manganese, chromium and iron containing thiazolidinylidene and pyridinylidene ligands. J. Chem. Soc., Dalton Trans. 1974, 760.

(16) Herrmann, W. A.; Ofele, K.; von Preysing, D.; Herdtweck, E. Metal complexes of acyclic diaminocarbenes: links between $\mathrm{N}$ heterocyclic carbene (NHC)- and Fischer-carbene complexes. J. Organomet. Chem. 2003, 684, 235.

(17) The electronic carbene stabilization effect of replacing the alkoxycarbene substituent with an amino group is well-documented. For recent representative examples, see: (a) Kvapilová, H.; Hoskovcová, I.; Ludvík, J.; Zálišs, S. Theoretical predictions of redox potentials of Fischer-type chromium aminocarbene complexes. Organometallics 2014, 33, 4964. (b) Landman, M.; Levell, T.; Pretorius, R.; Fraser, R.; Buitendach, B. E.; Conradie, M. M.; van Rooyen, P. H.; Conradie, J. Electrochemical behaviour and structure of novel phosphine- and phosphite-substituted tungsten(0) Fischer carbene complexes. Electrochim. Acta 2014, 130, 104. (c) Van der Westhuizen, B.; Swarts, P. J.; van Jaarsveld, L. J.; Liles, D. C.; Siegert, U.; Swarts, J. C.; Fernández, I.; Bezuidenhout, D. I. Substituent effects on the electrochemical, spectroscopic and structural properties of Fischer mono- and biscarbene complexes of chromium(0). Inorg. Chem. 2013, 52, 6674. (d) Chu, G. M.; Guerrero-Martínez, A.; Fernández, I.; Sierra, M. A. Tuning the photophysical properties of BODIPY molecurles by $\pi$-conjugation with Fischer carbene complexes. Chem. - Eur. J. 2014, 20, 1367.

(18) Tolman, C. A. Steric effects of phosphorous ligands in organometallic chemistry and homogeneous catalysis. Chem. Rev. 1977, 77, 313.

(19) (a) Chianese, A. R.; Li, X. W.; Jansen, M. C.; Faller, J. W.; Crabtree, R. H. Rhodium and iridium complexes of N-heterocyclic carbenes via transmetalation: Structure and dynamics. Organometallics 2003, 22, 1663. (b) Kelly, R. A., III; Clavier, H.; Giudice, S.; Scott, N. M.; Stevens, E. D.; Bordner, J.; Smardjiev, I.; Hoff, C. D.; Cavallo, L.; Nolan, S. P. Determination of N-heterocyclic carbene (NHC) steric and electronic parameters using the $\left[(\mathrm{NHC}) \operatorname{Ir}(\mathrm{CO})_{2} \mathrm{Cl}\right]$ system. Organometallics 2008, 27, 202.

(20) (a) Wang, D.; Astruc, D. The golden age of transfer hydrogenation. Chem. Rev. 2015, 115, 6621. (b) Brieger, G.; Nestrick, T. J. Catalytic transfer hydrogenation. Chem. Rev. 1974, 74, 567.

(21) Crabtree, R. H. Resolving heterogeneity problems and impurity artifacts in operationally homogeneous transition metal catalysts. Chem. Rev. 2012, 112, 1536.

(22) For selected relevant examples of $\operatorname{Ir}^{\mathrm{I}}$-NHC complexes employed as TH catalysts, see: (a) Gong, X.; Zhang, H.; Li, X. Iridium phosphine abnormal $\mathrm{N}$-heterocyclic carbene complexes in catalytic hydrogen transfer reactions. Tetrahedron Lett. 2011, 52, 5596. (b) Gulcemal, S.; Gokçe, A. G.; Çetinkaya, B. Iridium(I) Nheterocyclic carbene complexes of benzimidazole-2-ylidene: effect of electrondonating groups on the catalytic transfer hydrogenation 
reaction. Dalton Trans. 2013, 42, 7305. (c) Azua, A.; Mata, J. A.; Peris, E. Organometallics 2011, 30, 5532. (d) Jimenez, M. V.; FernandezTornos, J.; Perez-Torrente, J. J.; Modrego, F. J.; Winterle, S.; Cunchillos, C.; Lahoz, F. J.; Oro, L. A. Iridium(I) complexes with hemilabile N-heterocyclic carbenes: efficient and versatile hydrogenation catalyst. Organometallics 2011, 30, 5493. (e) Jimenez, M. V.; Fernandes-Tornos, J.; Modrego, F. J.; Perez-Torrente, J. J.; Oro, L. A. Oxidation and $\beta$-alkylation of alcohols catalysed by iridium(I) complexes with functionalised N-heterocyclic carbene ligands. Chem. - Eur. J. 2015, 21, 17877. (f) Mazloomi, Z.; Pretorius, R.; Pamies, O.; Albrecht, M.; Dieguez, M. Triazolylidene iridium complexes for highly efficient and versatile transfer hydrogenation of $\mathrm{C}=\mathrm{O}, \mathrm{C}=\mathrm{N}$, and $\mathrm{C}=\mathrm{C}$ bonds and for acceptorless alcohol oxidation. Inorg. Chem. 2017, 56, 11282 .

(23) (a) Zuo, W.; Lough, J.; Li, Y. F.; Morris, R. H. Amine(imine)diphosphine iron catalysts for asymmetric transfer hydrogenation of ketones and imines. Science 2013, 342, 1080. (b) Naik, A.; Maji, T.; Reiser, O. Iron(II)-bis(isonitrile) complexes: novel catalysts in asymmentric transfer hydrogenation of aromatic and heteroaromatic ketones. Chem. Commun. 2010, 46, 4475. (c) Hopewell, J. P.; Martins, J. E. D.; Johnson, T. C.; Godfrey, J.; Wills, M. Developing asymmetric iron and ruthenium-based cyclone complexes; complex factors influence the asymmetric induction in the transfer hydrogenation of ketones. Org. Biomol. Chem. 2012, 10, 134.

(24) (a) Pretorius, R.; Mazloomi, Z.; Albrecht, M. Synthesis, hemilability, and catalytic transfer hydrogenation activity of iridium(III) and ruthenium(II) complexes containing oxygen-functionalised triazolylidene ligands. J. Organomet. Chem. 2017, 845, 196. (b) Azua, A.; Finn, M.; Yi, H.; Beatriz Dantas, A.; Voutchkova-Kostal, A. Transfer hydrogenation from glycerol: activity and recyclability of iridium and ruthenium sulfonate functionalized $\mathrm{N}$-heterocyclic carbene catalysts. ACS Sustainable Chem. Eng. 2017, 5, 3963. (c) Popoola, S. A.; Jaseer, E. A.; Al-Saadi, A. A.; Polo, V.; Casado, M. A.; Oro, L. A. Iridium complexes as catalysts in the hydrogen transfer of isopropanol to acetophenone: Ligand effects and DFT studies. Inorg. Chim. Acta 2015, 436, 146. (d) Gnanamgari, E.; Sauer, E. L. O.; Schley, N. D.; Butler, C.; Incarvito, C. D.; Crabtree, R. H. Iridium and ruthenium complexes with chelating $\mathrm{N}$-heterocyclic carbenes: efficient catalysts for transfer hydrogenation, $\beta$-alkylation of alcohols, and N-alkylation of amines. Organometallics 2009, 28, 321. 